\title{
Prevalence of comorbidity in cancer patients scheduled for systemic anticancer treatment in Austria
}

\section{A cross-sectional multicentre observational study}

\author{
Marija Balic (D) - Wolfgang Hilbe · Sylvia Gusel · Michael Fiegl · Heinz Ludwig • Beate Mayrbäurl · Josef Thaler · \\ Hellmut Samonigg · Karin Hegenbarth · Florian Eisner - Brigitte Mlineritsch · Richard Greil · Maria \\ Johanna Schandl · Ansgar Weltermann - Andreas Petzer · David Fuchs · Wolfgang Stangl · Peter Krippl · \\ Reinhard Stauder · Herbert Stöger
}

Received: 22 July 2019 / Accepted: 29 October 2019 / Published online: 6 November 2019

(C) The Author(s) 2019

\begin{abstract}
Summary The purpose of this observational study was to determine the prevalence of comorbid conditions in cancer patients with solid tumours selected for specific treatment at 12 divisions of medical oncology in Austria. Data from 1137 patients were collected using a standardized questionnaire; of these, 1036 datasets were evaluable for further analysis. Data were prospectively collected from patients during an in- or outpatient hospital visit over a 4-month period in 2011. Of these patients $42 \%$ had gastrointestinal cancer, $31 \%$ had breast cancer, $9 \%$ lung cancer and the remaining had urogenital cancer, sarcoma or other types of rare cancers. Around two-thirds of patients had metastatic disease (59\%), confined to a single organ site in $55 \%$ of patients. A high pro-
\end{abstract}

We dedicate this study to our colleague, Ferdinand Ploner, who died in a tragic accident during the study.

Assoc. Prof. M. Balic, MDPhD (凶) · S. Gusel · H. Samonigg • K. Hegenbarth $\cdot$ F. Eisner $\cdot$ H. Stöger

Department of Oncology, Medical University Graz, Auenbruggerplatz 15, 8036 Graz, Austria marija.balic@medunigraz.at

W. Hilbe $\cdot$ H. Ludwig

Department of Oncology, Hematology and Palliative Care, Wilhelminen Hospital, Montleartstraße 37, 1160 Vienna, Austria

M. Fiegl • R. Stauder

Department of Oncology and Hematology, Medical

University Innsbruck, Innsbruck, Austria

B. Mayrbäurl · J. Thaler

Department for Internal Medicine, Klinikum

Wels-Grieskirchen, Wels, Austria portion of patients had a good performance status (Eastern Cooperative Oncology Group [ECOG] 0,1: $82 \%)$. Comorbid conditions were classified according to the Charlson scheme score and were present in $86 \%$ of patients with a median age of 64 years. The predominant conditions were cardiovascular diseases (57\%), metabolic diseases (44\%), endocrinological diseases $(30 \%)$, gastrointestinal diseases $(26 \%)$, neurological $(23 \%)$ and respiratory diseases $(23 \%)$. As has been reported by others we found a clear association between number of comorbid conditions and age. While $60 \%$ of the whole population had at least 2 comorbidities, most patients of the elderly population $(89 \%)$ had more than three comorbidities. The high proportion of patients with comorbidities and

\section{B. Mlineritsch · R. Greil}

Department of Internal Medicine III, Salzburg Cancer Research Institute-Centre for Clinical Cancer and Immunology Trials, Cancer Cluster Salzburg, Paracelsus Medical University Salzburg, Salzburg, Austria

M. Schandl $\cdot$ A. Weltermann $\cdot$ A. Petzer Ordensklinikum Linz, Linz, Austria

D. Fuchs

Keppler University Hospital Linz, Linz, Austria

W. Stangl

Hospital Oberwart, Oberwart, Austria

P. Krippl

Hospital Fürstenfeld, Fürstenfeld, Austria 
accompanying medication represents a substantial challenge for medical oncologists in selecting the optimal cancer-specific treatment especially in the era of novel targeted and immunotherapies. Comorbid conditions and accompanying comedications require special precautions concerning potential interactions and unexpected adverse reactions from prescribed tumour-specific treatment.

Keywords Drug interactions · Neoplasms · Multiple chronic conditions · Demographics · Adverse events

\section{Introduction}

In an age-adjusted view the overall cancer incidence and cancer mortality rates have declined slightly over the past decades. However, cancer incidence increases with age and due to the demographic changes with a growing older population the prevalence of cancer accumulates [1, 2]. In western countries more than $60 \%$ of newly diagnosed cancer patients are older than 65 years [3]. Cancer treatment strategies aim to either maximise survival and/or to relieve cancerassociated symptoms limited by risks of treatment-related side effects. In elderly patients the achievements of modern oncology treatments seem to be of less impact on survival than in younger patients indicating challenging aspects concerning the risk-benefit ratio [4]. Besides others, one major drawback may be the higher probability of comorbidity incidence in the aged population [5]. More than half of all cancer patients older than 50 years had at least one comorbidity and it was shown that with higher age the number of comorbidities increases [6]. Roger et al. reported that both cardiovascular disease and cancer are more prevalent with increasing age [7] with $38 \%$ of cancer patients suffering from hypertension [8]. The negative prognostic impact of comorbid conditions in cancer patients has been shown in numerous reports [9, 10] and may be the result of an inadequate individually unadjusted anticancer treatment. In addition, a higher probability of treatment-related toxicity could also affect patients' survival [11]. Moreover, Satariano et al. reported on an independent effect of comorbidity on survival in breast cancer patients regardless of age, extent of disease and treatment [12]. There is an increasing need for geriatric and social assessment in treatment planning in order to provide best treatment especially for elderly patients diagnosed with cancer.

The presence of comorbid conditions adds relevant complexity to the management of cancer patients by potential pharmacological interactions and unpredictable additional (new) toxicities induced by their accompanying comedications. At this time point we are lacking reliable data regarding this situation as patients with substantial comorbidities are generally excluded from participation in clinical cancer trials and vice versa cancer per se is an exclusion parameter for other trials. Consequently, anticancer drug develop- ment and their approval offer limited information relevant for daily routine treatment decisions. Therefore we face an urgent need on additional data dealing with real world patient cohorts to adopt to a more balanced risk-benefit evaluation. This initiative by the Austrian Society of Hematology and Oncology aims to illustrate the magnitude and impact of concomitant conditions in daily practice on a large cohort managed in daily routine.

\section{Materials and methods}

\section{Study population and material}

This hospital-based registry included cancer patients with solid tumours requiring systemic treatment admitted to 12 medical oncology departments in Austria. During a 4-month period in 2011 and based on predefined time spans, i.e. 5-10 working days, all patients admitted for treatment regardless of tumour stage were eligible and included in the study after written informed consent had been obtained. Information was gathered by means of a multi-item questionnaire including patients' demographic and clinical characteristics, current treatment intention, indication of the Eastern Cooperative Oncology Group (ECOG) performance status and comorbid condition classified according to the Charlson score [13]. Data were collected by treating physicians. The study was approved by the local ethical committee at the Medical University Graz.

\section{Patient characteristics}

In all, 1036 evaluable patients were included after informed consent was obtained: $56 \%$ were female and $44 \%$ were male, the majority of patients were older than 60 years of age $(60 \%)$. Age distribution showed that $31 \%$ were between 60 and 70 years and $30 \%$ were older than 70 years of age. Five percent were younger than 40 and $34 \%$ were between 40 and 60 years of age at the time of inclusion. Median age was 64 years (range 21-92 years). Metastatic disease was the underlying cause for systemic treatment planned in the majority of patients (58\%), fewer patients (39\%) received neo/adjuvant or curative and only $3 \%$ of the patients a definitive treatment. The type of malignancy was distributed as follows: breast cancer in $31 \%$, colorectal cancer in $25 \%$, upper gastrointestinal (GI) cancer (including pancreas) in 17\%, lung cancer in 9\%, genitourinary cancer in $8 \%$, and other (including sarcoma) in $9 \%$ of patients. In the presence of metastatic disease the predominant sites of metastatic involvement were liver, lung, bone and lymph nodes. Half of the patients presented with one metastatic site, $30 \%$ with two sites and $15 \%$ with multiple site involvement. 
Table 1 Adapted classification of comorbidity according to the Charlson scheme

\begin{tabular}{|c|c|}
\hline Cardiovascular diseases & $\begin{array}{l}\text { Myocardial infarction, angina pectoris, congestive heart failure, arrhythmia, valvular defect, } \\
\text { hypertension, peripheral vascular disease, cerebrovascular disease, venous thromboem- } \\
\text { bolism }\end{array}$ \\
\hline Metabolic diseases & Diabetes mellitus, hyperlipidaemia, adipositas \\
\hline Endocrine diseases & Thyroid disorders, osteoporosis, osteopenia, other endocrine disorders \\
\hline $\begin{array}{l}\text { Gastrointestinal/liver } \\
\text { diseases }\end{array}$ & Gastrointestinal bleeding, peptic ulcer, hepatic damage \\
\hline Neurological diseases & Polyneuropathy, dementia, depression \\
\hline Pulmonary disease & $\begin{array}{l}\text { Chronic obstructive pulmonary disease, bronchial asthma, pneumonia, pulmonary hyperten- } \\
\text { sion }\end{array}$ \\
\hline Renal diseases & Mild insufficiency, severe insufficiency \\
\hline $\begin{array}{l}\text { Cancer/immune and } \\
\text { infectious diseases }\end{array}$ & $\begin{array}{l}\text { Second primary tumour, lymphoma, leukaemia, myeloproliferative diseases, immunodeficien- } \\
\text { cies, AIDS, hepatitis, tuberculosis }\end{array}$ \\
\hline Miscellaneous & Anaemia, smoking habits, alcohol dependency \\
\hline
\end{tabular}

Table 2 Distribution of comorbidities in 1036 patients

\begin{tabular}{ll} 
Comorbid condition: & $n(\%)$ \\
\hline Cardiovascular disease & $590(57)$ \\
\hline Metabolic disease & $456(44)$ \\
\hline Endocrine disease & $311(30)$ \\
\hline Gastrointestinal/liver disease & $265(26)$ \\
\hline Neurological disease & $242(23)$ \\
\hline Pulmonary disease & $236(23)$ \\
\hline Renal disease & $132(13)$ \\
\hline Cancer/immune and infectious diseases/other & $153(15)$
\end{tabular}

\section{Results}

A total of 1137 questionnaires were collected in this 4-month period and evaluable data on 1036 patients were obtained. Data on comorbid conditions were extracted from clinical records, letters, medical history and current medication (Table 1). The presence of at least one comorbid condition was documented in $86 \%$ of the patients. Similar proportions of patients had one $(22 \%)$, two $(23 \%)$, three $(19 \%)$ or more than three $(22 \%)$ comorbid conditions. The distribution of comorbidities in our population is shown in Table 2. A comparable distribution of comorbidities was reported when referring to the different tumour entities with the exception of lung cancer patients, who were more likely to have a higher rate of comorbidities. Only $5 \%$ of these patients had no, $38 \%$ had 1 or 2 and the remaining $57 \%$ had at least 3 comorbid conditions. There was a clear association between the number of comorbidities and the age of the patients (these differences were statistically significant, chi-squared test $p<0.001$, Fig. 1). In our patient population cardiovascular diseases $(57 \%)$ and metabolic diseases $(44 \%)$ were predominantly seen, followed by

Fig. 1 Distribution of patients (\%) within particular age groups according to the numbers of comorbidities documented (these differences were statistically significant, chi-squared test $p<0.001)$

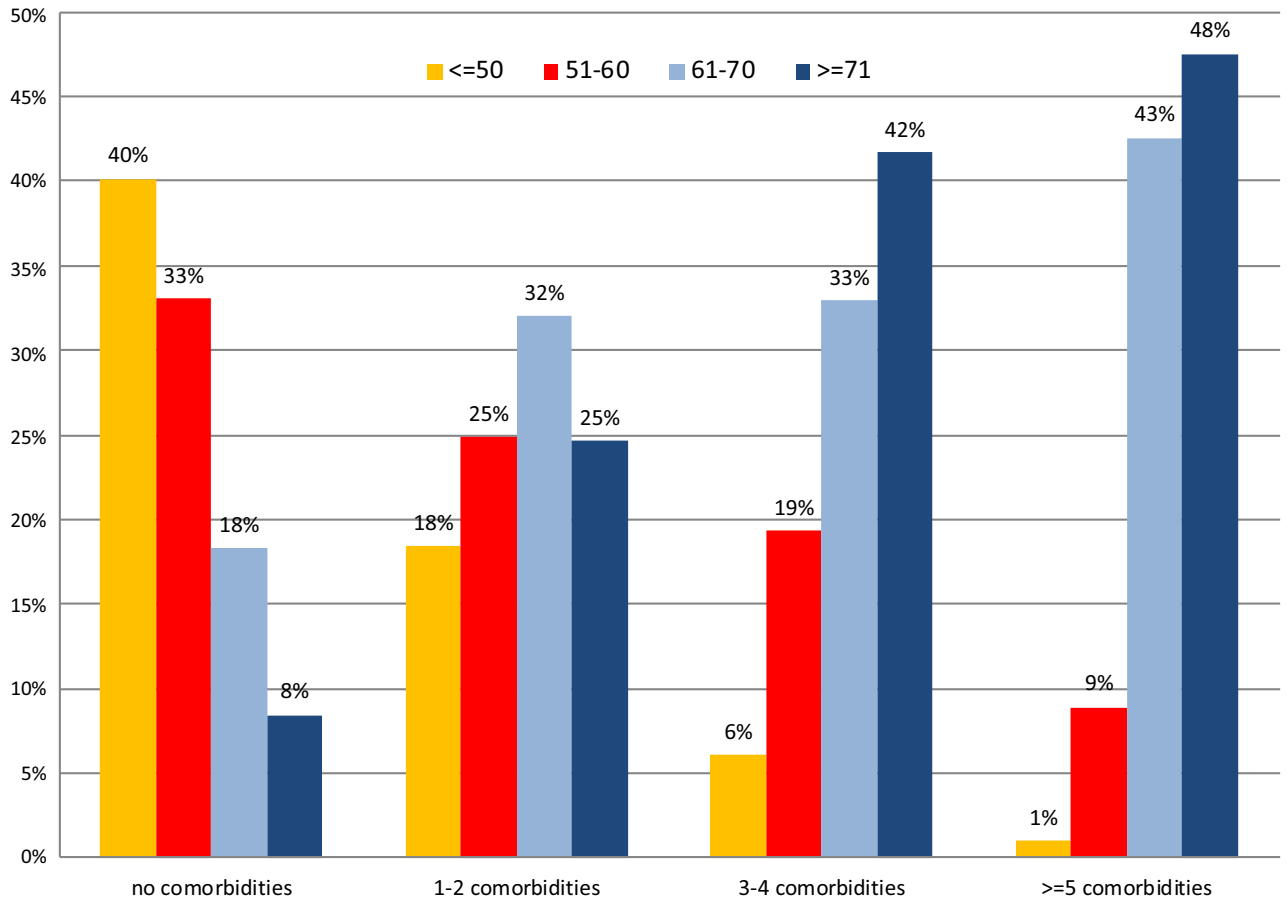


-ECOG 0 ECOG 1 ECOG 2 ECOG 3

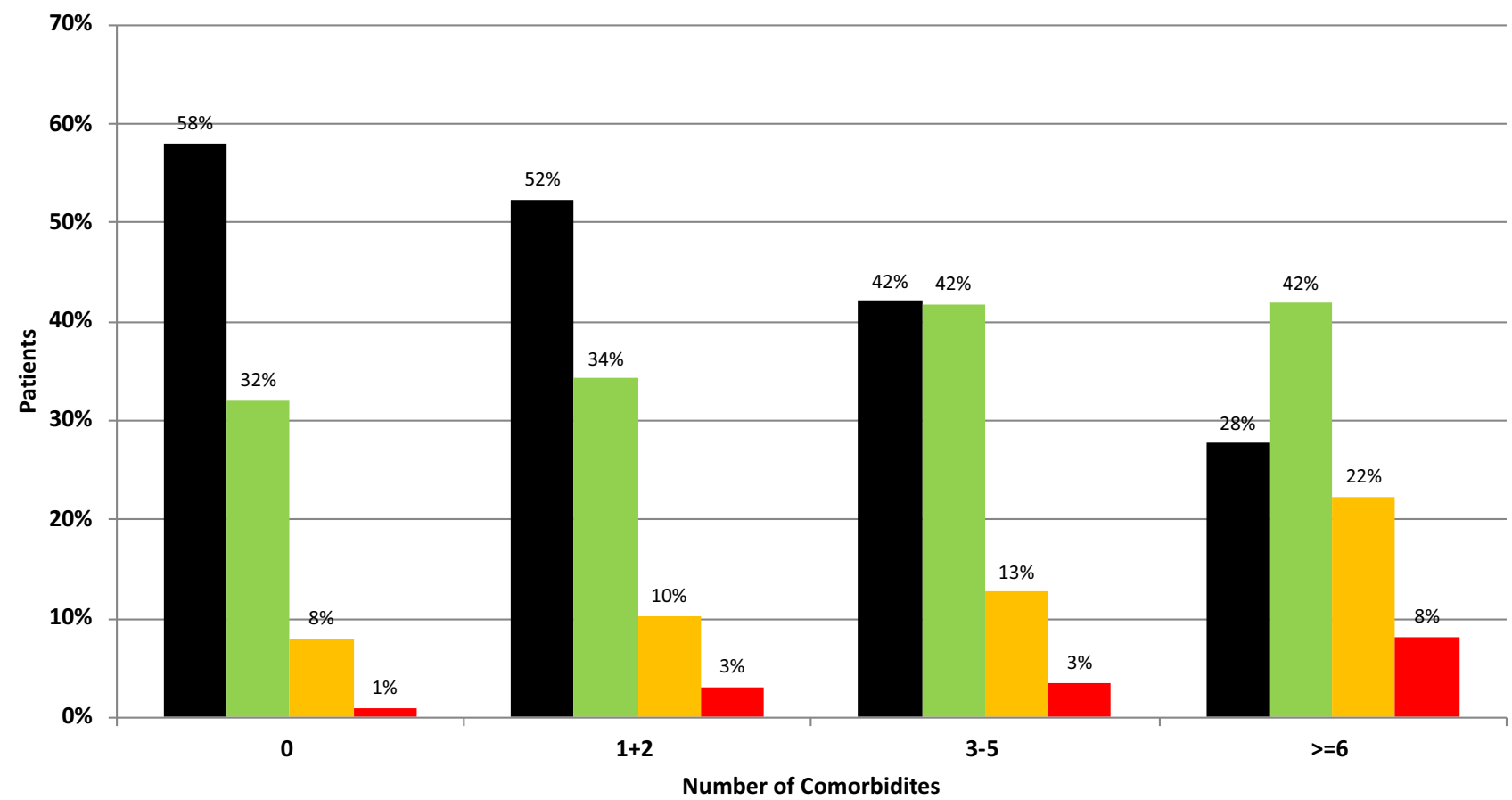

Fig. 2 Distribution of ECOG status of patients (\%) in relation to the numbers of comorbidities documented (these differences were statistically significant, chi-squared test $p<0.001)$. ECOG Eastern Cooperative Oncology Group

endocrine diseases (30\%). Among the patients with cardiovascular diseases $44 \%$ had hypertension, gastrointestinal (26\%), neurological $(23 \%)$ and diseases of the respiratory tract $(23 \%)$ and renal impairment $(13 \%)$.

A "low" comorbidity index (i.e. weighted Charlson index) was reported in $51 \%$, "moderate" in $38 \%$, "high" in $9 \%$, and "very high" in $2 \%$ of patients. Metastases and second primary cancers were not counted as a separate comorbidity in this analysis, since the aim of the study was to assess comorbid conditions potentially interacting with tumour treatment [14]. Otherwise, due to this fact more than two-thirds of patients would misleadingly have been allocated to the "very high" index group. Despite of the high proportion of patients with comorbid conditions (86\%), the vast majority (82\%) of the investigated population was in a good performance status (ECOG 0/1). We observed a significant association between increase in numbers of comorbid conditions and deterioration in performance status (chi-squared test $p<0.001$, Fig. 2).

Concerning the cancer-specific treatment, 598 of the patients $(58 \%)$ were allocated to receive palliative treatment, whereas for 409 patients (39\%) the treatment was in adjuvant, neoadjuvant or curative intention. The remaining 29 patients $(3 \%)$ were not clearly attributable to one of these treatment groups (e.g. definitive treatment with radiochemotherapy). The majority of patients treated (54\%) were assigned to receive chemotherapy, regardless of the intention of treatment. Another $17 \%$ of the patients received a combination of chemo- and targeted therapy. Of the remaining patients, $14 \%$ were planned for targeted therapy alone and $17 \%$ for hormonal treatment. As indicated above, the majority of the patients (86\%) allocated for treatment had at least one documented comorbid condition. Even patients with no comorbidity and with a good performance status, used medications other than those for cancer-specific treatment. We observed a significant correlation of number of medications prescribed in relation to the amount of comorbid conditions (chi-squared test $p<0.001$, Fig. 3). Only $13 \%$ of the investigated population did not take any additional drug regardless of comorbidities and disease status. Patients who were assigned to get palliative tumour-specific treatment were more likely to have a higher number of comedications. There was a statistically significant increase in the number of medications prescribed in relation to the allocated cancer-specific treatment (chi-squared test $p<0.001$; Fig. 4).

\section{Discussion}

Our study demonstrates that a high proportion of patients had at least one comorbidity although in good performance status. Comorbid conditions were present in $86 \%$ of patients.

This study was performed in 2011, and since then an increasing number of different systemic treatments 


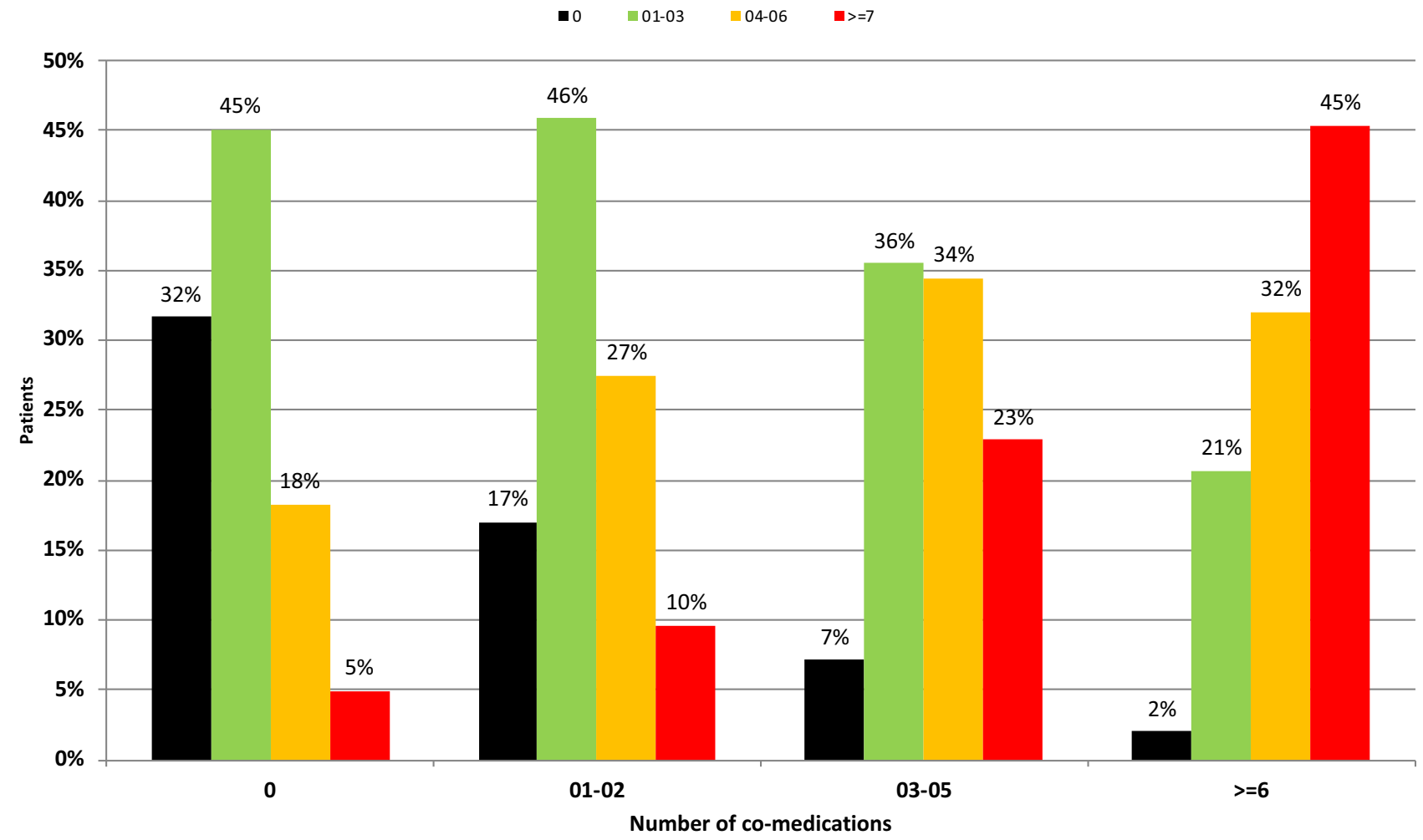

Fig. 3 Number of medications prescribed in relation to the amount of comorbid conditions (these differences were statistically significant, chi-squared test $p<0.001$ )

Fig. 4 Number of medications prescribed in relation to the allocated cancer-specific treatment (these differences were statistically significant, chisquared test $p<0.001$ )

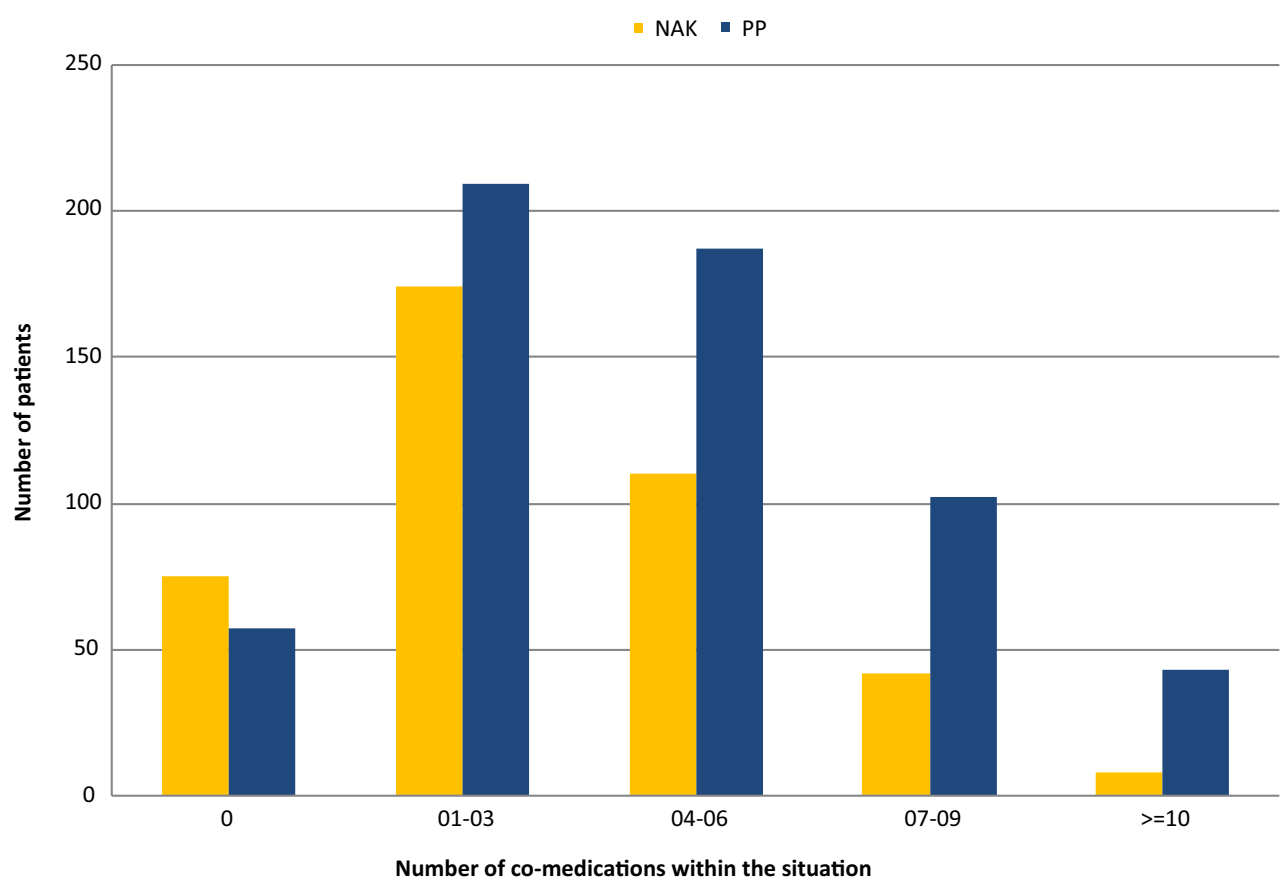

including a great number of novel tyrosine kinase inhibitors (TKIs) and diversity of immunotherapies were approved and are now used in patients with solid tumours. The awareness of comorbidities and comedications and their impact on prognosis of cancer patients along with a greater potential of drug interactions and increasing toxicity has therefore gained great importance. The performance status of the patient based on the comorbidities and their comedications has increasingly been taken into benefit-risk evaluation of different treatments and recently, practical management ASCO guidelines have been published for elderly patients [15] to improve patients' management and selection. 
Substantial increase of approved novel drugs in management of cancer patients offer new treatment options, but at the same time, a high rate of comorbidities and also older patients in the representative population in daily oncological practice is challenging a balanced treatment decision. The selection of drugs, dosing and safe prescription and administration are critical, considering the polypharmaceutical medication of the comorbid patients, particularly in the elderly. Others have already shown that comorbidities are correlated with an increased risk for toxicities, reduced treatment delivery and minor outcome when compared with a less comorbid patient cohort.

Profound knowledge on noncancer diseases is mandatory for medical oncologists, since comorbidities may exacerbate under anticancer treatment, e.g. diabetes (steroid-induced) or heart failure, coronary heart disease or other vascular diseases with lifethreatening potential both due to worsening of preexisting diseases or due to drug interaction (e.g. interaction with anticoagulation inducing bleeding). Recently, also the need for immunosuppressive drugs due to autoimmune diseases has come into focus, which became particularly important with the introduction of immune checkpoint inhibitors.

Our study performed on 1137 patients scheduled for cancer-specific treatment by using a standardized questionnaire exemplifies the magnitude of the clinical problem, demonstrating high prevalence of comorbid conditions with $83 \%$ of the patients having at least one comorbidity. Lung cancer patients had the highest prevalence, with $95 \%$ proven to have a concomitant comorbid condition. Furthermore, in the cohort of patients older than 70 years less than $10 \%$ of patients were free from any comorbidities, which is in line with the published literature [16].

In our evaluated population, an increase in the number of comorbid conditions, when disregarding their severity, did not correlate directly with worsening of the performance status. But in contrast to for example Coebergh et al., we did not limit comorbidities to serious diseases, as the purpose of our study was to indicate the potential of interaction of comorbidities with specific treatment planning and not to show an impact on survival [6].

Two-thirds of our patients were in palliative setting and 50\% were planned for the first-line therapy. One-third of patients were in the curative setting (i.e. neoadjuvant, adjuvant or curative setting). In contrast, although the population in our series presented on average with a good performance status, we observed a high number of patients (87\%) taking comedication regardless of the underlying reason.

These findings are important as various factors including comorbidity may lead to a higher risk of cancer treatment-related toxicity, as shown by Hurria et al. who developed a valuable prediction score in this regard [17]. Treatment-related toxicity may lead to an inferior outcome, which is also influenced by either delayed diagnosis or limited use of chemotherapy in patients with comorbidities $[10,18]$. Just one example of novel treatments and the needed caution when treating patients who are more commonly having both higher frequency of comorbidities and of comedications is given by the higher rate of increased toxicity of CDK 4/6 inhibitors in elderly compared to younger patients.

Facing these concerns about the possibility of increased toxicity clinicians are less likely to offer standard chemotherapy or most effective treatment to elderly patients or patients with comorbidities and are prone to accept even less efficacy or limited benefit of and alternative treatment chosen $[19,20]$. Due to increasing importance of comorbidities and elderly in cancer treatment, guidelines have been published to support balanced decisions and trials are being designed to specifically address this population of patients $[21,22]$.

On the other hand, lacking data on elderly and/or comorbid patients might lead to a misleading assumption of a safe drug application, which is especially true for newer drugs, e.g. anti-VEGF antibodies, TKIs or novel immunotherapies, resulting in more complications and toxicities than reported in randomised trials [23].

Comedication is of special interest due to the fact that modern biologicals-especially TKIs-have the potential of interaction at the metabolizing cytochrome P-450 enzyme system (CYP) or drug transporters $[24,25]$. Due to a large degree of interindividual variability of these enzymes, overlapping toxicities and pharmacokinetic interactions of targeted therapies with various accompanying comedications have to be taken into consideration in patients with comorbid conditions [26]. Findings from our observational study underline the importance of not only taking the individual patient's cancer stage into consideration, but also comorbidities and comedication when deciding on individual tumour-specific treatment. The risk-benefit evaluation in the daily oncology practice situation may substantially differ from a highly biased clinical trial scenario. Individualized medical evaluation and thorough clinical judgement may be necessary to avoid additional toxicities and to preserve appropriate efficacy.

\section{Conclusions}

The high proportion of patients with comorbidities and corresponding medication represents a substantial challenge for medical oncologists in selecting the optimal tumour-specific treatment. These conditions require special precautions in order to avoid potential interactions and unexpected adverse reactions from prescribed cancer-specific treatment and indicate that there is an increasing need for multidisciplinary care and treatment decisions [27]. Systemic anticancer treatment of an elderly and comorbid patient pop- 
ulation deserves a profound knowledge in the management of noncancerous diseases. Therefore, the central role of a medical oncologist within interdisciplinary teams for a holistic perception of an individual cancer patient is stressed and implicates that young oncologists should receive comprehensive training in the management of the most relevant noncancerous diseases to be handled in an elderly population.

Funding Open access funding provided by Medical University of Graz.

Conflict of interest M. Balic, W. Hilbe, S. Gusel, M. Fiegl, H. Ludwig, B. Mayrbäurl, J. Thaler, H. Samonigg, K. Hegenbarth, F. Eisner, B. Mlineritsch, R. Greil, M. Schandl, A. Weltermann, A. Petzer, M. Fuchs, W. Stangl, P. Krippl, R. Stauder, and H. Stöger declare that they have no competing interests.

Open Access This article is distributed under the terms of the Creative Commons Attribution 4.0 International License (http://creativecommons.org/licenses/by/4.0/), which permits unrestricted use, distribution, and reproduction in any medium, provided you give appropriate credit to the original author(s) and the source, provide a link to the Creative Commons license, and indicate if changes were made.

\section{References}

1. Siegel RL, Miller KD, Jemal A. Cancer statistics, 2016. Ca Cancer J Clin. 2016;66(1):7-30.

2. Zeber JE, Copeland LA, Hosek BJ, Karnad AB, Lawrence VA, Sanchez-Reilly SE. Cancer rates, medical comorbidities, and treatment modalities in the oldest patients. Crit Rev OncolHematol. 2008;67(3):237-42.

3. Aapro MS, Kohne CH, Cohen HJ, Extermann M. Never too old? Age should not be a barrier to enrollment in cancer clinical trials. Oncologist. 2005;10(3):198-204.

4. QuagliaA, TavillaA, ShackL, Brenner H, Janssen-Heijnen M, Allemani C, et al. The cancer survival gap between elderly and middle-aged patients in Europe is widening. Eur J Cancer. 2009;45(6):1006-16.

5. Guralnik JM. Assessing the impact of comorbidity in the older population. Ann Epidemiol. 1996;6(5):376-80.

6. Coebergh JW, Janssen-Heijnen ML, Post PN, Razenberg PP. Serious co-morbidity among unselected cancer patients newly diagnosed in the southeastern part of The Netherlands in 1993-1996. JClin Epidemiol. 1999;52(12):1131-6.

7. Roger VL, Go AS, Lloyd-Jones DM, Adams RJ, Berry JD, Brown TM, et al. Heart disease and stroke statistics-2011 update: a report from the American Heart Association. Circulation. 2011;123(4):e18-e209.

8. Piccirillo JF, Tierney RM, Costas I, Grove L, Spitznagel EL Jr. Prognostic importance of comorbidity in a hospital-based cancer registry. JAMA. 2004;291(20):2441-7.

9. Read WL, Tierney RM, Page NC, Costas I, Govindan R, Spitznagel EL, et al. Differential prognostic impact of comorbidity. JClin Oncol. 2004;22(15):3099-103.

10. Lee L, Cheung WY, Atkinson E, Krzyzanowska MK. Impact of comorbidity on chemotherapy use and outcomes in solid tumors: a systematic review. J Clin Oncol. 2011;29(1):106-17.

11. Geraci JM, Escalante CP, Freeman JL, Goodwin JS. Comorbid disease and cancer: the need for more relevant conceptual models in health services research. J Clin Oncol. 2005;23(30):7399-404.

12. Satariano WA, Ragland DR. The effect of comorbidity on 3 -year survival of women with primary breast cancer. Ann Intern Med. 1994;120(2):104-10.
13. Charlson ME, Pompei P, Ales KL, MacKenzie CR. A new method of classifying prognostic comorbidity in longitudinal studies: development and validation. J Chronic Dis. 1987;40(5):373-83.

14. Mariotto AB, Wang Z, Klabunde CN, Cho H, Das B, Feuer EJ. Life tables adjusted for comorbidity more accurately estimate noncancer survival for recently diagnosed cancer patients. JClin Epidemiol. 2013;66(12):1376-85.

15. Mohile SG, Dale W, Somerfield MR, Hurria A. Practical assessment and management of vulnerabilities in older patients receiving chemotherapy: aSCO guidelinefor geriatric oncology summary. JOP. 2018;14(7):442-6.

16. Janssen-Heijnen ML, Schipper RM, Razenberg PP, Crommelin MA, Coebergh JW. Prevalence of co-morbidity in lung cancer patients and its relationship with treatment: a population-based study. Lung Cancer. 1998;21(2):105-13.

17. Hurria A, Togawa K, Mohile SG, Owusu C, Klepin HD, Gross CP, et al. Predicting chemotherapy toxicity in older adults with cancer: a prospective multicenter study. J Clin Oncol. 2011;29(25):3457-65.

18. Houterman S, Janssen-Heijnen ML, Verheij CD, Louwman WJ, Vreugdenhil G, van der Sangen MJ, et al. Comorbidity has negligible impact on treatment and complications but influences survival in breast cancer patients. Br J Cancer. 2004;90(12):2332-7.

19. Sarfati D, Hill S, Blakely T, Robson B, Purdie G, Dennett E, et al. The effect of comorbidity on the use of adjuvant chemotherapy and survival from colon cancer: a retrospective cohort study. BMCCancer. 2009;9:116.

20. Gross CP, McAvay GJ, Guo Z, Tinetti ME. The impact of chronic illnesses on the use and effectiveness of adjuvant chemotherapy for colon cancer. Cancer. 2007;109(12):2410-9.

21. Perrone F, Nuzzo F, Di Rella F, Gravina A, Iodice G, Labonia $\mathrm{V}$, et al. Weekly docetaxel versus CMF as adjuvant chemotherapy for older women with early breast cancer: final results of the randomized phase III ELDA trial. Ann Oncol. 2015;26(4):675-82.

22. Stockler MR, Harvey VJ, Francis PA, Byrne MJ, Ackland SP, Fitzharris B, et al. Capecitabine versus classical cyclophosphamide, methotrexate, and fluorouracil as firstline chemotherapy for advanced breast cancer. JClin Oncol. 2011;29(34):4498-504.

23. Hershman DL, Wright JD, Lim E, Buono DL, Tsai WY, Neugut AI. Contraindicated use of bevacizumab and toxicity in elderly patients with cancer. J Clin Oncol. 2013;31(28):3592-9.

24. Krause DS, Van Etten RA. Tyrosine kinases as targets for cancer therapy. NEngl J Med. 2005;353(2):172-87.

25. Haouala A, Widmer N, Duchosal MA, Montemurro M, Buclin T, Decosterd LA. Drug interactions with the tyrosine kinase inhibitors imatinib, dasatinib, and nilotinib. Blood. 2011;117(8):e75-e87.

26. Haouala A, Zanolari B, Rochat B, Montemurro M, Zaman K, DuchosalMA, etal. Therapeutic drugmonitoring of thenew targeted anticancer agents imatinib, nilotinib, dasatinib, sunitinib, sorafenib and lapatinib by LC tandem mass spectrometry. J Chromatogr B Analyt Technol Biomed Life Sci. 2009;877(22):1982-96.

27. Goede V, Stauder R. Multidisciplinary care in the hematology clinic: implementation of geriatric oncology. J Geriatr Oncol. 2019;10(3):497-503.

Publisher's Note Springer Nature remains neutral with regard to jurisdictional claims in published maps and institutional affiliations. 